\title{
Nurse Managers Stress and Coping
}

\author{
AChiharu Miyata ${ }^{*}$, Hidenori Arai $^{2}$, Sawako Suga ${ }^{3}$ \\ ${ }^{1}$ Department of Human Health Sciences, Kyoto University Graduate School of Medicine, Kyoto, Japan \\ ${ }^{2}$ National Center for Geriatrics and Gerontology, Obu, Aichi, Japan \\ ${ }^{3}$ Department of Health Sciences, Kyoto Tachibana University, Kyoto, Japan \\ Email: "miyata.chiharu.4m@kyoto-u.ac.jp
}

Received 7 October 2015; accepted 2 November 2015; published 5 November 2015

Copyright (C) 2015 by authors and Scientific Research Publishing Inc.

This work is licensed under the Creative Commons Attribution International License (CC BY).

http://creativecommons.org/licenses/by/4.0/

(c) (i) Open Access

\begin{abstract}
Objective: The purpose of this study was to gain insight into nurse managers' stress experiences and coping strategies in order to better support them. Design: A qualitative exploratory descriptive research design was used in this study. Subject: Fifteen nurse managers participated in this study. Results: Three descriptive themes related to nurse managers' occupational stress were identified: role overload, loneliness, and role conflict. We also identified three descriptive themes that contributed to their stress management: sufficient support and advice, taking mental breaks while off duty, and individual coping strategies. Conclusions: Our study proposes two recommendations to reduce nurse managers' stress. First, for nurse managers who experience work overload, hospitals should support them in learning how to work efficiently and how to manage their response to work demands. Second, nurse managers' primary stressors were loneliness and role conflict. Nurse managers are known to juggle multiple demands from the hospital nursing director and staff nurses. Although it is difficult to eliminate the role conflict, nurse managers should be guided on how to manage conflicting demands, the hospital nursing director and staff nurses.
\end{abstract}

\section{Keywords}

Nurse Managers, Role Stressors, Role Conflict, Coping Strategy

\section{Introduction}

Over the last decade, management in nursing has become increasingly demanding [1]. Nurse managers' roles have undergone a significant change as they take on more administrative management, and they now have much broader responsibilities for direct patient care, managing staff nurses, leadership, and organizational resource management. Shirey [2] reviewed the expansion of the nurse manager role from 1980 to 2003 and found increased demands on nurse managers, which led to increased job stress. Since this review was published, many

\footnotetext{
*Corresponding author.
} 
other studies had supported Shirey's assertion that the nurse manager's role tends to be inherently demanding and stressful. A recent review indicates that nurse managers' leadership styles are responsible for creating healthy workplaces that will attract and retain the best nurses [3]. In addition, another study found that nurse managers have a significant impact on the health of their staff [4], and nurse managers' stress has been shown to be related to staff nurses' decreased satisfaction [5]. Thus, the poor health of nurse managers indirectly and negatively affects their staff's health. Furthermore, a number of studies [6] [7] have shown that nurse managers can be vulnerable and therefore at the risk of ill health and decreased psychological well-being. Nurse managers cannot perform their duties at a high level of professionalism without good health, and therefore, their health is clearly important. However, most of the research has focused on the stress of novice nurses and staff nurses in Japan, whereas few researchers have studied nurse managers' stressors. Therefore, the aim of this study was to address nurse managers' stress and coping strategies, and two research questions were developed based on this aim.

The research questions were as follows:

1) What are nurse managers' occupational stressors?

2) How do nurse managers cope with their stress?

\section{Aim}

The aim of this study was to gain insight into nurse managers' perceptions of stress and to learn their coping strategies.

\section{Review of the Literature}

Work-related mental health results primarily from increased workplace satisfaction and from mitigating workrelated stress. Among nurses, specific environmental stressors have been identified, including unpredictable staffing and scheduling, lack of role clarity, little involvement in decision-making, poor status, and poor support [8]. Studies on nursing that specifically focus on nurse managers have focused more on the negative organizational outcomes from ineffective nurse managers than on their personal stress. For example, the nurse manager role is critical for organizational success, patient outcomes, and staff job satisfaction and empowerment [9]-[11]. However, most of the studies have focused on the effects of nurse managers' stress and have shown that it is induced by role overload, role ambiguity, fiscal responsibilities, inadequate human resources, and intrapersonal distress [12] [13]. In addition, Lee and Cummigs [14] reported that workload is negatively related to nurse managers' job satisfaction. Shirey et al. [15] conducted a qualitative study that focused on a variety of negative outcomes related to the stress of being a nurse manager. These included emotions such as anger, guilt, frustration, aggravation, and worry, as well as health outcomes such as sleeplessness, irritability, restlessness, impatience, exhaustion, shortness of breath, and tense muscles. These results have been supported by recent quantitative research that links nurse managers' stress with lower job satisfaction, lower organizational commitment, higher turnover intentions, and increased physical and mental health symptoms [12]. Another study revealed that some nurse managers thrive on the complexity of the role and enjoy the opportunity to lead others to achieve their personal, professional, and organizational goals, but others reported negative physical and psychological effects of role stress [16].

\section{Study Design}

A qualitative exploratory descriptive research design was used to gain an in-depth understanding of nurse managers' stress and coping strategies using semi-structured interviews.

\subsection{Method}

Data were collected from July to August 2012. All face to face interviews were conducted by researcher. The study was completed when the data has been saturated. Interview topic guide designed by researchers and experts from the faculty of psychology. The questions on the interview guide focused on the views of the job-stress of nurses [17]. Six questions were addressed using a qualitative descriptive approach:

1) What are the major occupational stressors that you face as a nurse manager?

2) How do you deal with your concerns? 
3) Does your hospital offer any support?

4) Can you cope with your stress positively?

5) What do you do when you feel tired or stressed?

6) What do you think is the effect of your mental health on your staff?

All interviews lasted for 30 to 60minutes and were audio recorded in a private room at each hospital.

\subsubsection{Study Inclusion Criteria}

Fifteen nurse managers participated in this study. They were selected from five hospitals with 200 beds or more in the Kanto, Kansai, and Kyushu regions of Japan. Criterion sampling was used for intentional sampling, and each person had at least one year of experience as a nurse

\subsubsection{Ethical Consideration}

The study was approved by the Ethics Committee of the Kyoto University Graduate School and the Faculty of Medicine. Additionally, research permission was given by the nursing department directors of all five hospitals. After receiving approval from each hospital, we explained the project and procedures to the nurse managers.

\subsection{Data Analysis}

Data analysis was done simultaneously with data collection. The authors independently reviewed the transcriptions and constructed tables of code categories based on actual words or phrases (meaning units). We independently identified themes that represented one or more code categories and specific quotations that represented each code category; this qualitative content analysis approach was adapted from Graneheim and Lundman [18]. The researchers discussed the coding and the major themes that emerged from the data to reach consensus. Rigor and trustworthiness were ensured by our following qualitative principles and ensuring that there was a clear audit trail of the descriptive exploratory findings. Data analysis encompassed description, interpretation, and thematic development. Themes were emergent based on the data. The patterns identified offered an account that related to and answered the research questions.

\section{Findings}

Participant Characteristics (Table 1).

Table 1. Demographic characteristics of the nurse managers.

\begin{tabular}{cccc}
\hline Age Mean (SD): 46.8 (6.0) & $\begin{array}{r}\text { Experience as a nurse } \\
\text { manager (years): 5.1 (2.3) }\end{array}$ & Academic background & Work unit Subhead \\
\hline 44 & 2 & Diploma in nursing & Education \\
47 & 5 & Diploma in nursing & Outpatient \\
50 & 1 & Diploma in nursing & Internal medicine ward \\
50 & 9 & Graduate university & Surgery ward \\
44 & 8 & Diploma in nursing & Intensive care unit \\
47 & 7 & Junior college graduate & Internal medicine ward \\
45 & 6 & Junior college graduate & Orthopedics ward \\
51 & 7 & Diploma in nursing & Surgery ward \\
50 & 4 & Diploma in nursing & Internal medicine ward \\
45 & 5 & Junior college graduate & Stroke care unit \\
49 & 7 & Junior college graduate & Dental oral surgery ward \\
46 & 3 & Junior college graduate & Gastrointestinal and breast surgery ward \\
46 & 3 & Junior college graduate & Cardiovascular ward \\
47 & 4 & Junior college graduate & Respiratory, blood and oncology ward \\
42 & 5 & Junior college graduate & High care unit \\
\hline
\end{tabular}


The nurse managers were all women. The mean age was 46.8 years (range: 42 - 50 years). Mean years of work experience as a nurse manager was 5.1 years (range: one to nine years).

\subsection{Stress Source}

Three descriptive themes related to nurse managers' stressors were identified: role overload, loneliness, and role conflict (Table 2).

\subsubsection{Role Overload}

Role overload consisted of four subcategories: juggling many business roles; scheduling and coordinating human relationships; working with patients and families; and receiving numerous off-duty phone calls. Numerous and complex demands from staff members, colleagues, and families and multiple administrative duties caused overload, and high expectations also challenged nurse managers, who were asked to do too much for too many people in too little time. The nurse manager role has expanded over the years, mostly reflected in their greater responsibility for their staffs. The interviewees reported feeling overwhelmed, as reflected in the following comments:

"There is not enough time during the day. There are high expectations from staff, other health care professionals, and patients. There is not enough time during the day to manage multiple meetings, deal with patients' and families' complaints, and respond to staff needs.”

"I've often said, if there were no staff allocation problem, this job would be good to do. Yet indeed, staff allocation is a pain in the neck and gets me down day after day."

\subsubsection{Loneliness}

The second major stressor identified by the participants was the sense of loneliness or isolation. This theme encompassed two subcategories: being solely responsible for managing ward-related problems and being unable to express fatigue because of the influence on staff members. Nurse managers expressed that because they could not share management problems with their chiefs and staff members, they worried about and experienced their problems on their own; they could not express their worries because of the influence on others, and they felt lonely. "We are stressed... a nurse manager is really lonely. I can consult the chief or staff members in my ward, but there are many things I cannot talk to them about—so I am carrying around the worries on my own".

\subsubsection{Role Conflict}

Role conflict consisted of two subcategories. Participants described feeling squeezed between conflicting demands: organizational performance targets from above and staff expectations from below and additional expectations from physicians and other department leaders, as reflected in the following comments:

"I do many things to improve the quality of nursing care. But sometimes it does not match the hospital policy. I can understand the feeling of the staff, but...”

"I consult the other department leaders and the physician about patient care. Sometimes, I feel anger, but it is not possible to show the anger."

\subsection{Nurse Managers' Coping Strategy}

We also identified three descriptive themes related to their coping strategies: sufficient support and advice, taking

\begin{tabular}{|c|c|}
\hline Theme & Sub-Category \\
\hline Role overload & $\begin{array}{l}\text { multiple business roles } \\
\text { scheduling, coordinating human relationships } \\
\text { working with patients and families } \\
\text { numerous off-duty phone calls }\end{array}$ \\
\hline Loneliness & $\begin{array}{l}\text { managing ward-related problems alone } \\
\text { inability to show fatigue because of the influence on staff members. }\end{array}$ \\
\hline Role conflict & $\begin{array}{l}\text { being caught between conflicting demands } \\
\text { managing anger }\end{array}$ \\
\hline
\end{tabular}


mental breaks when off duty, and general coping (Table 3).

\subsubsection{Sufficient Support and Advice}

Regarding coping strategies, nearly half of the participants cited this theme as a significant stress mitigator. The theme consisted of three subcategories: advice from other administrators and nursing directors; sharing information with other nurse managers; and a hospital consulting system. Interviewee comments included:

"Fortunately, the senior nurse manager and vice nursing director listen to me. I receive advocating advice and criticism, too, but I feel happy that I can talk about my concerns to somebody else.”

"I would be very happy if there were an opportunity to share all my concerns with other nurse managers after work and receive appropriate advice from senior nurses.”

\subsubsection{Taking Mental Breaks When off Duty}

Another factor that decreased participants' stress was taking mental breaks while they were off duty. This theme consisted of two subcategories: awareness of the importance of taking time off and recognizing physical symptoms such as fatigue. Participants were aware of the need to take time off in order to reduce their stress and expand their chief nurses' training. Participants' comments included:

"I think we need to take some rest. Some nurse managers work all the time without taking rest, so I believe we need rest."

"In the past, even if I took rest, I received many phone calls, so I couldn't take sufficient rest. Today, I transferred my responsibility to the chief nurse so I can take rest. I think it improves the chief's motivation as well.”

\subsubsection{Individual Coping Strategies}

This theme encompassed four subcategories: thinking positively; enhancing one's private life; separating private life from work; and identifying individual effective strategies. Stress-related emotions differed between the novice and experienced nurse managers, and coping strategies differed depending on the nurse manager's experience.

One novice nurse manager (with less than four years of experience) consulted other nurse managers as her coping strategy. Another eleven participants (who had more than four years of experience) spoke of coping strategies such as maintaining enriched relationships with their families, taking private time, and completely shifting from work to private life. Participants' comments included the following:

"I would say that the first thing to do for stress coping is to talk with other nurse managers." (a novice nurse manager)

"I have been in this position for seven years, and I have had a lot to learn. I am always trying not to think about my work when I am off duty and to give my attention to other areas such as my family.” (an experienced nurse manager)

\section{Discussion}

Role overload and role conflict, which were extracted as stressors for nurse managers in this study, were consistent with the results obtained in other developed countries [13] [19]. Some researchers have suggested that nurse managers have the most demanding work schedules in the health care sector [20]. In addition, the scope of responsibilities, span of control, and work demands may be unrealistic for nurse managers [21] [22]. Role ambi-

\begin{tabular}{cl}
\hline \multicolumn{1}{c}{ Table 3. Nurse managers’ coping strategy. } \\
\hline Theme & \multicolumn{1}{c}{ Sub-Category } \\
\hline Sufficient support and advice & $\begin{array}{l}\text { advice from administrators and nursing directors } \\
\text { sharing information with other nurse managers } \\
\text { hospital consultation systems }\end{array}$ \\
Taking mental breaks when off duty & $\begin{array}{l}\text { awareness of the importance of taking time off } \\
\text { recognizing physical symptoms such as fatigue }\end{array}$ \\
& $\begin{array}{l}\text { thinking positively } \\
\text { enhancing private life } \\
\text { Individual coping strategies }\end{array}$ \\
& $\begin{array}{l}\text { keeping work and private life separate } \\
\text { devising personal coping strategies }\end{array}$ \\
\hline
\end{tabular}


guity and diversity are considered to contribute to the excessive number of roles nurse managers must serve [12] [19], and the same situation is seen in Japan. Further, in Japan, there is little recognition of nurse managers' roles as nursing administrators among both the managers and staff nurses. As such, nurse managers tend to assume both administrative and staff management duties, which increase their workloads and complicate their work.

Next, the theme of coping strategies, such as seeking advice from superiors and coworkers and developing individual coping strategies, supported the results from previous studies. The increasing span of control is reported to cause effects such as lack of mentoring, increased stress, and decreased job satisfaction [23]. In this study, all participants mentioned the efficacy and importance of coping strategies, and when nurse managers did not have much experience, seeking advice from senior nurses and/or superiors and sharing their concerns with other nurse managers led to relaxation. In addition, in the past, nurse managers managed and monitored their wards on their own, and therefore, they had to remain at the hospital and never take a day off. However, they have recently become aware of the need to take time off in order to reduce their stress and expand their chief nurses' training.

By contrast, however, the sense of isolation that was extracted as a stressor in this study was not reported in other studies. Limited recognition of nurse managers' roles as administrators and their inability to manage stress are considered the background for the above. In particular, it was difficult for novice nurse managers to establish personal coping methods. Therefore, it is necessary to provide novice nurse managers with opportunities to seek advice from experienced managers so that they are not isolated on their wards and their stress does not increase. Further, nurses' need for continuing stress management education has been reported from clinical sites. Nurse managers are expected to achieve organizational objectives while establishing a healthy workplace for the staff in their units [24]. Therefore, we insist that the nurse managers who must care for their staff members' psychosomatic health must have sufficient stress management skills. Finally, lack of knowledge related to hospital operations, such as budgets and cost reduction, which was reported as a stressor in a number of previous studies, was not identified in this study [19]. However, in recent years, nursing directors in Japan have come to concurrently serve as hospital deputy directors, which require their greater knowledge of business and business administration. As a result, this new status may emerge as a new stressor in the future.

This study extracted general stress-related factors; "role conflict" and "sense of isolation" as stressors and "recognizing the need to rest" as a coping strategy were the primary factors extracted in this study, but the contents of specific stressors were not extracted. Therefore, in the future, it is necessary to collect quantitative data to supplement this study's results with specific individual stressors, using questionnaires. The study results suggest the need to establish a system in which nurse managers' duties are clearly defined and they can receive consultation and advice to reduce their stress.

\section{Recommendations}

In this study, we aimed to identify nurse managers' occupational stressors and coping strategies through interviews. The results can be utilized for future nurse manager stress management, including offering suggestions for reducing stress. In addition, for nurse managers who feel overloaded, hospitals should support them in learning how to work efficiently and how to manage their responses to their job demands. Nurse managers are known to juggle multiple demands from hospital nursing directors and staff nurses. Although it is difficult to eliminate role conflict, nurse managers should be given a safe place to discuss their concerns and receive advice on how to manage their conflicting demands.

\section{Conclusion}

We found that nurse managers' occupational stressors were role overload, loneliness, and role conflict, and their coping strategies included receiving sufficient support and advice from other administrators and nursing directors and taking mental breaks when they were off duty. However, individual coping strategies were very different. The nurse managers in this study appeared to recognize the impact of their stress on other staff members and also appeared to be aware of stress management strategies.

\section{Acknowledgements}

We thank all the nurses who took time from their busy schedules to participate in this study. 


\section{References}

[1] Hyrkäs, K. (2005) Clinical Supervision, Burnout and Job Satisfaction among Mental Health and Psychiatric Nurses in Finland. Issues in Mental Health Nursing, 26, 531-556. http://dx.doi.org/10.1080/01612840590931975

[2] Shirey, M.R. (2006) Stress and Coping in Nurse Manager: Two Decades of Research. Nursing Economics, 24, 193-211.

[3] Cummings, G.G., MacGregor, T., Davey, M., Lee, H., Wong, C.A., Lo, E., Muise, M. and Stafford, E. (2010) Leadership Styles and Outcome Patterns for the Nursing Workforce and Work Environment: A Systematic Review. International Journal of Nursing Studies, 47, 363-385. http://dx.doi.org/10.1016/j.ijnurstu.2009.08.006

[4] Nyberg, A., Bernin, P., Theorell, T., Westerlund, H., Vahtera, J. and Kivimäki, M. (2009) Managerial Leadership and Ischemic Heart Disease among Employees: The Swedish WOLF Study. Occupational and Environmental Medicine, 66, 51-55. http://dx.doi.org/10.1136/oem.2008.039362

[5] Meyer, R.M., O’Brien-Pallas, L., Doran, D., Streiner, D., Ferguson-Pare, M. and Duffield, C.M. (2011) Front-Line Managers as Boundary Spanners: Effects of Span and Time on Nurse Supervision Satisfaction. Journal of nursing management, 19, 611-622. http://dx.doi.org/10.1111/j.1365-2834.2011.01260.x

[6] Lindholm, M., Dejin-Karlsson, E., Ostergren, P.O. and Udén, G. (2003) Nurse Managers Professional Networks, Psychosocial Resources and Self-Rated Health. Journal of Advanced Nursing, 42, 506-515. http://dx.doi.org/10.1046/j.1365-2648.2003.02650.x

[7] Luchinger, H.K.S., Almost, J., Purdy, N. and Kim, J. (2004) Predictors of Nurse Managers’ Health in Canadian Restructured Healthcare Settings. Nursing Leadership, 17, 88-105. http://dx.doi.org/10.12927/cjnl.2004.17020

[8] Williams, S., Michie, S. and Pattani, S. (1998) Improving the Health of the NHS Workforce. The Nuffield Trust, London.

[9] Duffield, C.M., Roche, M.A., Blay, N. and Stasa, H. (2011) Nursing Unit Managers, Staff Retention and the Work Environment. Journal of Clinical Nursing, 20, 23-33. http://dx.doi.org/10.1111/j.1365-2702.2010.03478.x

[10] Lucas, V., Laschinger, H.K.S. and Wong, C.A. (2008) The Impact of Emotional Intelligent Leadership on Staff Nurse Empowerment: The Moderating Effect of Span of Control. Journal of Nursing Management, 16, 964-973. http://dx.doi.org/10.1111/j.1365-2834.2008.00856.x

[11] Wong, C.A., Laschinger, H.K.S. and Cummings, G.G. (2010) Authentic Leadership and Nurses’ Voice Behavior and Perceptions of care Quality. Journal of Nursing Management, 18, 889-900. http://dx.doi.org/10.1111/j.1365-2834.2010.01113.x

[12] Kath, L.M., Stichler, J.F. and Ehrhart, M.G. (2012) Moderators of the Negative Outcomes of Nurse Manager Stress. Journal of Nursing Administration, 42, 215-221. http://dx.doi.org/10.1097/NNA.0b013e31824ccd25

[13] Udod, S.A. and Care, W.D. (2011) Nurse Managers’ Work Stressors and Coping Experiences: Unravelling the Evidence. Canadian Journal of Nursing Leadership, 24, 57-72. http://dx.doi.org/10.12927/cjnl.2011.22601

[14] Lee, H. and Cummings, G.G. (2008) Factors Influencing Job Satisfaction of Front Line Nurse Managers: A Systematic Review. Journal of Nursing Management, 16, 768-783. http://dx.doi.org/10.1111/j.1365-2834.2008.00879.x

[15] Shirey, M.R., Ebright, P.R. and McDaniel, A.M. (2008) Sleepless in America: Nurse Managers Cope with Stress and Complexity. Journal of Nursing Administration, 38, 125-131. http://dx.doi.org/10.1097/01.NNA.0000310722.35666.73

[16] Paliadelis, P.S., Cruickshank, M. and Sheridan, A. (2007) Caring for Each Other: How Do Nurse Managers "Manage” Their Role? Journal of Nursing Management, 15, 830-837. http://dx.doi.org/10.1111/j.1365-2934.2007.00754.X

[17] Kageyama, T., Nishikido, N., Kobayashi, T., Oga, J. and Kawashima, M. (2003) The Relationship of Work Stress to the Mental Health Status of Female Nurses in a Public Hospital. Japanese Journal of Nursing and Health Sciences, 4, 1-10. (In Japanese)

[18] Graneheim, U. and Lundman, B. (2004) Qualitative Content Analysis in Nursing Research: Concepts, Procedures and Measures to Achieve Trustworthiness. Nurse Education Today, 24, 105-112. http://dx.doi.org/10.1016/j.nedt.2003.10.001

[19] McCallin, A.M. (2010) The Role of the Charge Nurse Manager: A Descriptive Exploratory Study. Journal of Nursing Management, 18, 319-325. http://dx.doi.org/10.1111/j.1365-2834.2010.01067.x

[20] Anthony, M.K., Standing, T.S. and Glick, J. (2005) Leadership and Retention: The Pivotal Role of Nurse Managers. Journal of nursing Administration, 35, 146-155. http://dx.doi.org/10.1097/00005110-200503000-00008

[21] Judkins, S., Massey, C. and Huff, B. (2006) Hardiness, Stress, and Use of Ill-Time among Nurse Managers: Is There A Connection? Nursing Economics, 24, 187.

[22] Shirey, M.R. (2007) AONE Leadership Perspectives: Competencies and Tips for Effective Leadership: From Novice to 
Expert. Journal of Nursing Administration, 37, 167-170. http://dx.doi.org/10.1097/01.NNA.0000266842.54308.38

[23] Silvetti, C., Rudan, V., Frederickson, K. and Sullivan, B. (2000) Where Will Tomorrow'S Nurse Managers Come From? Journal of Nursing Administration, 30, 157-159. http://dx.doi.org/10.1097/00005110-200004000-00002

[24] Espinoza, D.C., Lopez-Saldana, A. and Stonestreet, J.S. (2009) The Pivotal Role of the Nurse Manager in Healthy Workplaces: Implications for Training and Development. Critical Care Nursing Quarterly, 32, 327-334.

http://dx.doi.org/10.1097/CNQ.0b013e3181bad528 